\title{
Caracterização fenotípica e molecular de genitores de feijão tipo carioca quanto à resistência a patógenos
}

\author{
Carlos Lasaro Pereira de Melo(1), Vilmar Antônio Ragagnin ${ }^{(2)}$, Klever Marcio Antunes Arruda( ${ }^{(3)}$, \\ Everaldo Gonçalves de Barros ${ }^{(4)}$, Pedro Crescêncio Souza Carneiro(4), Trazilbo José de Paula Júnior ${ }^{(5)}$, \\ Maurilio Alves Moreira( ${ }^{(6)}$ e José Eustáquio de Souza Carneiro( ${ }^{(7)}$
}

\begin{abstract}
(1)Embrapa Agropecuária Oeste, Caixa Postal 661, CEP 79804-970 Dourados, MS. E-mail: lasaro@cpao.embrapa.br (2)Universidade Federal de Goiás, Rodovia BR 364, Km 192, Setor Industrial, CEP 75800-000 Jataí, GO. E-mail: varagagnin@yahoo.com.br (3)Universidade Federal de Viçosa (UFV), Instituto de Biotecnologia Aplicada à Agropecuária, Laboratório de Genética Molecular de Plantas, s/no, CEP $36571-000$ Viçosa, MG. E-mail: kleverantunes@yahoo.com.br (4)UFV, Departamento de Biologia Geral. E-mail: ebarros@ufv.br, carneiro@ufv.br (5)Empresa de Pesquisa Agropecuária de Minas Gerais, Caixa Postal 216, CEP 36571-000 Viçosa, MG. E-mail: trazilbo@epamig.ufv.br ${ }^{(6)}$ UFV, Departamento de Bioquímica e Biologia Molecular. E-mail: moreira@ufv.br (7)UFV, Departamento de Fitotecnia. E-mail: jesc@ufv.br
\end{abstract}

Resumo - O objetivo deste estudo foi a caracterização fenotípica e molecular de 31 genótipos de feijão do tipo carioca, quanto à resistência aos patógenos da antracnose, ferrugem e mancha-angular. Foram realizadas inoculações com 13 patótipos de Colletotrichum lindemuthianum, dois de Uromyces appendiculatus e sete de Pseudocercospora griseola. Na caracterização molecular, foram utilizados cinco marcadores moleculares previamente identificados, ligados a diferentes alelos de resistência aos patógenos. Sete genótipos apresentaram resistência a 12 patótipos de $C$. lindemuthianum. Nove genótipos apresentaram resistência a cinco patótipos de P. griseola. Dez genótipos foram resistentes aos patótipos de U. appendiculatus. As linhagens VC 2, VC 3 e VC 5, além da Rudá-R (linhagem piramidada com cinco genes que conferem resistência a alguns patótipos de antracnose, ferrugem e mancha-angular), foram as que se destacaram quanto à resistência múltipla aos patógenos acima citados. Foi detectado polimorfismo molecular entre a maioria dos genótipos com a Rudá-R, o que indica a possibilidade de uso dos marcadores moleculares SCARF10, SCARY20, SCARAZ20, SCARH13 e OPX11.

Termos para indexação: Colletotrichum lindemuthianum, Phaseolus vulgaris, Pseudocercospora griseola, Uromyces appendiculatus, marcador molecular, melhoramento do feijoeiro.

\section{Phenotypic and molecular characterization of genitors of carioca-type common bean regarding their resistance to pathogens}

\begin{abstract}
The present study aimed at the phenotypic and molecular characterization of 31 genotypes of the carioca-type common bean regarding the resistance to anthracnose, rust and angular leaf spot (ALS) pathogens. Thirteen pathotypes of Colletotrichum lindemuthianum, two of Uromyces appendiculatus and seven of Pseudocercospora griseola were inoculated. In the molecular characterization, five molecular markers, identified in advance, and linked to the different alleles of pathogens' resistance, were used. Seven genotypes showed resistance to 12 pathotypes of $C$. lindemuthianum. Nine genotypes presented resistance to five pathotypes of $P$. griseola. Ten genotypes were resistant to the pathotypes of $U$. appendiculatus. The lines VC 2, VC 3 and VC 5, besides Rudá-R (line pyramided with five genes which confer resistance to some pathotypes of anthracnose, rust and ALS), were the stood out for multiple resistance to the pathogens above described. Molecular polymorphism was detected between the most genotypes with Rudá-R, which indicates the possibility of using the molecular markers SCARF10, SCARY20, SCARAZ20, SCARH13 and OPX11.
\end{abstract}

Index terms: Colletotrichum lindemuthianum, Phaseolus vulgaris, Pseudocercospora griseola, Uromyces appendiculatus, molecular markers, common bean improvement.

\section{Introdução}

A antracnose, a ferrugem e a mancha-angular são doenças foliares do feijoeiro causadas, respectivamente, pelos fungos Colletotrichum lindemuthianum (Sacc. \& Magnus) Scribner, Uromyces appendiculatus var. appendiculatus (Pers.) Unger e Pseudocercospora griseola (Sacc.) Crous \& U. Braun, que causam sérios prejuízos à produtividade de grãos, especialmente nas safras da 
seca e de outono-inverno (Paula Júnior \& Zambolim, 2006).

Apesar do intenso trabalho desenvolvido por diversos programas de melhoramento do feijoeiro no Brasil, até o presente momento não se dispõem de cultivares de feijão, de grãos do tipo carioca, com ampla resistência a essas doenças. Cultivares de grão carioca lançadas recentemente apresentam resistência a alguns patótipos de C. lindemuthianum, U. appendiculatus e P. griseola, porém são altamente suscetíveis a outros (Del Peloso et al., 2004; Faria et al., 2004; Sartorato et al., 2004). O uso contínuo de uma cultivar resistente, associado à grande variabilidade genética desses patógenos, pode fazer com que a resistência, normalmente monogênica, deixe de se expressar após algumas safras.

Uma dificuldade dos programas de melhoramento do feijoeiro é que, geralmente, cultivares com características agronômicas favoráveis como alta produtividade e bom aspecto comercial dos grãos são suscetíveis aos principais patótipos de C. lindemuthianum, U. appendiculatus e $P$. griseola. Além disso, há grande complexidade em se associar resistência ampla a diferentes patógenos, em uma única linhagem, apenas com uso de métodos convencionais de melhoramento. Por isso, tem sido enfatizada a associação de métodos convencionais com a seleção assistida por marcadores moleculares, como na obtenção da linhagem Rudá-R, em que cinco genes de resistência aos patógenos - da antracnose $(\mathrm{Co}-4$, Co-6 e Co-10), ferrugem ( $U r$-ON) e mancha-angular (Phg-1) - foram piramidados (Alzate-Marin et al., 2005).

Desde o lançamento da cultivar Rudá, em 1995, outras cultivares de grão carioca, com grãos de melhor aceitação comercial, têm sido disponibilizadas, nem sempre com bons níveis de resistência aos principais patótipos de C. lindemuthianum, U. appendiculatus e P. griseola (Embrapa, 2008). A cultivar Pérola, por exemplo, é suscetível à maioria dos patótipos de $C$. lindemuthianum (Paula Júnior \& Zambolim, 2006). Assim, tem-se procurado incorporar a resistência aos principais patótipos desses patógenos, em linhagens de feijão que apresentam grãos de boa aceitação comercial. Nesse contexto, a isolinha Rudá-R se constitui em excelente fonte de resistência e com a vantagem do conhecimento de marcadores moleculares RAPD ("random amplified polymorphic DNA") e SCAR ("sequence characterized amplified regions") associados a esses genes.
A caracterização fenotípica e molecular dos potenciais genitores a serem intercruzados é etapa fundamental na seleção assistida por marcadores moleculares que vise resistência a doenças.

Este estudo teve como objetivo a caracterização fenotípica e molecular de 31 genótipos de feijão de grãos do tipo carioca, quanto à resistência a patótipos de C. lindemuthianum, U. appendiculatus e P. griseola e à presença dos respectivos marcadores ligados aos alelos de resistência.

\section{Material e Métodos}

Foram avaliados 31 genótipos de feijão do tipo carioca, provenientes de diversos programas de melhoramento do feijoeiro do Brasil (Tabela 1), juntamente com as cultivares TO (portadora do gene de resistência Co-4), AB 136 (Co-6), AND 277 (Phg-1) e Ouro Negro ( $U r-O N$ e $\mathrm{Co}-10$ ). Essas cultivares foram utilizadas como fontes de genes de resistência, pelo Programa de

Tabela 1. Procedências dos genótipos de feijão utilizados na caracterização fenotípica e molecular.

\begin{tabular}{ll}
\hline Genótipos & Procedências \\
\hline Carioca 1070 & Instituto Agronômico do Paraná (Iapar) \\
CNFC 8017 & Embrapa Arroz e Feijão \\
CNFC 9437 & Embrapa Arroz e Feijão \\
CNFC 9500 & Embrapa Arroz e Feijão \\
FT Bonito & FT - Pesquisa e Sementes \\
GEN 12 & Instituto Agronômico de Campinas (IAC) \\
GEN 12-2 & Instituto Agronômico de Campinas (IAC) \\
IAPAR-81 & Instituto Agronômico do Paraná (Iapar) \\
LH-11 & Universidade Federal de Lavras (Ufla) \\
LP 98-20 & Instituto Agronômico do Paraná (Iapar) \\
LP 98-76 & Instituto Agronômico do Paraná (Iapar) \\
LP-98-31 & Instituto Agronômico do Paraná (Iapar) \\
OPS-82 & Universidade Federal de Lavras (Ufla) \\
Pérola & Embrapa Arroz e Feijão \\
Talismã & UFV/Ufla/Embrapa/Epamig \\
UTF-0013 & Cefet - Pato Branco \\
UTF-0019 & Cefet - Pato Branco \\
UTF-0029 & Cefet - Pato Branco \\
UTF-0030 & Cefet - Pato Branco \\
UTF-0031 & Cefet - Pato Branco \\
UTF-0037 & Cefet - Pato Branco \\
UTFB-0018 & Cefet - Pato Branco \\
UTFB-0022 & Cefet - Pato Branco \\
VC 2 & Universidade Federal de Viçosa (UFV) \\
VC 3 & Universidade Federal de Viçosa (UFV) \\
VC 4 & Universidade Federal de Viçosa (UFV) \\
VC 5 & Universidade Federal de Viçosa (UFV) \\
Vi 0699C & Universidade Federal de Viçosa (UFV) \\
Vi-4599C & Universidade Federal de Viçosa (UFV) \\
Vi-4899C & Universidade Federal de Viçosa (UFV) \\
Rudá-R &
\end{tabular}


Melhoramento do Feijoeiro, do Instituto de Biotecnologia Aplicada à Agropecuária (Bioagro/UFV).

A caracterização fenotípica das linhagens, com inoculações artificiais dos patógenos, foi realizada em casa de vegetação e em câmaras de nevoeiro do Bioagro/UFV. A multiplicação dos patógenos, o preparo de inóculo e a genotipagem das plantas foram realizados no Laboratório de Genética Molecular de Plantas, do Bioagro/UFV.

A avaliação da reação à $C$. lindemuthianum foi realizada com uso de, em média, 12 plantas de cada um dos 31 genótipos, além das cultivares Rudá (testemunha suscetível), TO, AB 136 e Ouro Negro (testemunhas resistentes), para cada patótipo de $C$. lindemuthianum testado. Foram utilizados os patótipos $65,67,73,81,83$, $85,87,89,95,117,453$ e 593 , de diferentes regiões geográficas, representativas das principais áreas produtoras de feijão no Brasil (Tabela 2), identificados por Alzate-Marin \& Sartorato (2004), com exceção do patótipo 593, identificado por Silva (2004). Foi utilizado também o patótipo 2047, caracterizado por Balardin et al. (1997). Esses patótipos, com exceção do 2047, são os mais freqüentes no campo, no Brasil (Pio-Ribeiro \&
Chaves, 1975; Alzate-Marin \& Sartorato, 2004). As culturas monospóricas originais dos patótipos foram cedidas pela Embrapa Arroz e Feijão. O preparo do inóculo e as inoculações foram feitos de acordo com a metodologia adaptada de Pio-Ribeiro \& Chaves (1975).

As sementes foram semeadas diretamente em bandejas de plástico $(60 \times 40 \times 12 \mathrm{~cm})$, com mistura de solo e esterco bovino curtido (4:1), adubada no momento do preparo com $5 \mathrm{~kg} \mathrm{~m}^{-3}$ do formulado NPK 4-14-8. As plantas foram mantidas em casa de vegetação até o momento da inoculação de $C$. lindemuthianum, que foi realizada dez dias após a semeadura, no início do estádio V2, tendo-se utilizado suspensão $1,2 \times 10^{6}$ conídios $\mathrm{mL}^{-1}$, aplicada em ambas as superfícies das folhas primárias, com o auxílio de um atomizador De Vilbiss no 15 , acionado por compressor elétrico. Em seguida, as plantas foram incubadas por cinco dias em câmara de nevoeiro $\left(20 \pm 1^{\circ} \mathrm{C}\right.$ e umidade relativa acima de $95 \%$ ), com fotoperíodo de 12 horas. Após a incubação, a avaliação dos sintomas de antracnose foi feita com base na escala de notas de 1 a 9, descrita por Van Schoonhoven \& Pastor-Corrales (1987). Foram avaliadas todas as

Tabela 2. Origens geográficas dos diferentes patótipos de Colletotrichum lindemuthianum (CL), Pseudocercospora griseola (PG) e Uromyces appendiculatus (UA), utilizados na caracterização fenotípica de genótipos de feijão do tipo carioca.

\begin{tabular}{|c|c|c|c|c|c|c|c|c|c|c|c|c|c|c|c|c|c|c|}
\hline \multirow[t]{2}{*}{ Patótipos } & \multirow[t]{2}{*}{ Patógeno } & \multirow[t]{2}{*}{ Origem } & \multicolumn{16}{|c|}{ Estados do Brasil } \\
\hline & & & $\mathrm{Al}$ & BA & DF & ES & GO & MG & MS & PB & $\mathrm{PE}$ & PR & RJ & $\mathrm{RR}$ & $\mathrm{RS}$ & $\mathrm{SC}$ & SE & SP \\
\hline $65^{(1)}$ & CL & Brasil & & $\mathrm{X}$ & $X$ & $\mathrm{X}$ & $\mathrm{X}$ & $\mathrm{X}$ & $X$ & $X$ & & $\mathrm{X}$ & & & $\mathrm{X}$ & $\mathrm{X}$ & & \\
\hline $67^{(1)}$ & CL & Brasil & & & & $\mathrm{X}$ & & & & & & & & & & & & \\
\hline $73^{(1)}$ & CL & Brasil & & & $\mathrm{X}$ & $\mathrm{X}$ & $\mathrm{X}$ & & $\mathrm{X}$ & & & $\mathrm{X}$ & $\mathrm{X}$ & & $\mathrm{X}$ & $\mathrm{X}$ & & $\mathrm{X}$ \\
\hline $81^{(1)}$ & CL & Brasil & & $X$ & $\mathrm{X}$ & & $X$ & $\mathrm{X}$ & $\mathrm{X}$ & & $\mathrm{X}$ & $\mathrm{X}$ & & & & $\mathrm{X}$ & & $\mathrm{X}$ \\
\hline $83^{(1)}$ & CL & Brasil & & & & & $\mathrm{X}$ & $\mathrm{X}$ & & & & & & & & & & \\
\hline $85^{(1)}$ & CL & Brasil & & & & & & $\mathrm{X}$ & & & & & & & & & & \\
\hline $87^{(1)}$ & CL & Brasil & & $X$ & $X$ & $\mathrm{X}$ & $\mathrm{X}$ & $X$ & & $X$ & $\mathrm{X}$ & $\mathrm{X}$ & & & $\mathrm{X}$ & $X$ & & \\
\hline $89^{(1)}$ & $\mathrm{CL}$ & Brasil & & & & & $\mathrm{X}$ & $\mathrm{X}$ & $\mathrm{X}$ & & & $\mathrm{X}$ & & & & $X$ & $X$ & \\
\hline $95^{(1)}$ & CL & Brasil & & & & & & & & & & $\mathrm{X}$ & & & & $X$ & & \\
\hline $117^{(1)}$ & CL & Brasil & & & & & $\mathrm{X}$ & & & & & & & & & & & \\
\hline $453^{(1)}$ & CL & Brasil & & & & & & & & & & $\mathrm{X}$ & & & $\mathrm{X}$ & & & \\
\hline $593^{(2)}$ & CL & Brasil & & & & & $X$ & & & & & & & & & & & \\
\hline $2047^{(3)}$ & CL & Costa Rica & & & & & & & & & & & & & & & & \\
\hline $31.15^{(4)}$ & PG & Brasil & & & & & $X$ & & & & & & & & & & & \\
\hline $31.23^{(4)}$ & PG & Brasil & & & & & $X$ & $\mathrm{X}$ & & & & & & & & & & \\
\hline $31.39^{(4)}$ & PG & Brasil & $X$ & & & & $X$ & $X$ & & & & & & $X$ & & & & \\
\hline $63.19^{(4)}$ & PG & Brasil & & & & $X$ & & $X$ & & & & & & & & & & \\
\hline $63.23^{(4)}$ & PG & Brasil & & & & & $\mathrm{X}$ & $X$ & & & & & & & & $\mathrm{X}$ & & \\
\hline $63.31^{(4)}$ & PG & Brasil & & & & $\mathrm{X}$ & $X$ & $\mathrm{X}$ & $\mathrm{X}$ & & & $\mathrm{X}$ & & & & $X$ & & \\
\hline $63.55^{(4)}$ & PG & Brasil & & & & & $X$ & X & & & $\mathrm{X}$ & & & & & & & \\
\hline $29-3^{(5)}$ & UA & Brasil & & & & & & $\mathrm{X}$ & & & & & & & & & & \\
\hline $63-3^{(5)}$ & UA & Brasil & & & & & & $X$ & & & & & & & & & & \\
\hline
\end{tabular}

(1)Patótipos identificados por Alzate Marin \& Sartorato (2004). (2)Patótipo identificado por Silva (2004). (3)Patótipo caracterizado por Balardin et al. (1997). ${ }^{(4)}$ Patótipos identificados por Sartorato \& Alzate Marin (2004). ${ }^{(5)}$ Patótipos reclassificados por Souza (2005). 
plantas, 12 em média, tendo-se realizado a identificação dos sintomas nas folhas unifolioladas e nos caules. Genótipos que apresentaram notas médias de 1 a 3, e acima de 3,1 foram considerados resistentes e suscetíveis, respectivamente.

A caracterização fenotípica da reação à ferrugem foi realizada com 12 plantas de cada um dos 31 genótipos, além das cultivares Rudá (testemunha suscetível) e Ouro Negro (testemunha resistente), para os dois patótipos de U. appendiculatus testados (Tabela 2). Os patótipos de $U$. appendiculatus utilizados foram classificados e identificados por Faleiro et al. (1999) e reclassificados por Souza (2005) e, de acordo com esses autores, estão entre os mais freqüentes e virulentos no Estado de Minas Gerais. O preparo do solo, a adubação e a condução das plantas, até o momento da inoculação, foram feitos como nos ensaios com antracnose.

A inoculação de $U$. appendiculatus foi realizada quando as folhas primárias apresentavam aproximadamente $2 / 3$ de seu desenvolvimento completo, cerca de dez dias após a semeadura. Os uredósporos, à concentração de $2 \times 10^{4}$ esporos $\mathrm{mL}^{-1}$, foram suspensos em água destilada, com $0,05 \%$ de Tween 20, e aspergidos em ambas as superfícies foliares. Após rápida secagem ao ar, as plantas foram transferidas para a câmara de nevoeiro $\left(20 \pm 1^{\circ} \mathrm{C}\right.$ e umidade relativa acima de $\left.95 \%\right)$, onde permaneceram por 48 horas, com fotoperíodo de 12 horas. Após esse período, as plantas foram mantidas em casa de vegetação $\left(20 \pm 5^{\circ} \mathrm{C}\right)$, onde permaneceram por 15 dias.

A avaliação dos sintomas de ferrugem foi feita na fase adaxial das folhas primárias, tendo-se considerado seis graus de reação, de acordo com a escala de notas de 1 a 6, proposta por Stavely et al. (1983). Os genótipos que apresentaram graus médios de 1 a 3 foram considerados resistentes, e os com graus 3,1 ou superiores, suscetíveis. Foi adotada essa classificação de resistência e suscetibilidade, com base na ausência de esporulação do fungo em genótipos com médias de nota até 3 .

A caracterização da resistência à mancha-angular foi realizada com 12 plantas, de cada um dos 31 genótipos, e das cultivares Rudá (testemunha suscetível) e AND 277 (testemunha resistente), para cada patótipo de P. griseola testado. As sementes foram semeadas em vasos de plástico de 3,5 L de capacidade, com três sementes por vaso. $\mathrm{O}$ preparo do solo, a adubação e a condução das plantas, até o momento da inoculação, foram feitos como descrito nos ensaios anteriores.
Foram utilizados os patótipos 31.15, 31.23, 31.39, 63.19, 63.23, 63.31 e 63.55 (Tabela 2) de P. griseola, classificados por Nietsche et al. (2001). O inóculo de cada patótipo foi produzido em placas de Petri com meio à base de extrato de tomate e ágar. A inoculação foi realizada após o aparecimento da primeira folha trifoliolada, estádio de desenvolvimento V3, aproximadamente 15 dias após a emergência das plantas, em ambas as superfícies foliares, com uma suspensão previamente ajustada para a concentração de $2 \times 10^{4}$ conídios $\mathrm{mL}^{-1}$. Os procedimentos de incubação foram feitos de maneira semelhante à descrita para o ensaio com ferrugem.

A severidade da mancha-angular foi avaliada aos 21 dias após a inoculação, com uso de uma escala de nove graus, descrita por Van Schoonhoven \& PastorCorrales (1987). A avaliação foi realizada em todas as folhas trifolioladas, de todas as plantas. Os genótipos que apresentaram graus médios de reação de 1 a 3 foram consideradas resistentes, e as com graus 3,1 ou maiores, suscetíveis.

Para a caracterização molecular dos 31 genótipos, foram coletadas nove folhas de cada genótipo, para a extração do DNA e posterior amplificação com marcadores moleculares ligados aos alelos de resistência a C. lindemuthianum, U. appendiculatus e $P$. griseola, previamente identificados em diversas etapas do Programa de Melhoramento de Feijão, do Bioagro/UFV. O DNA foi amplificado com os marcadores SCARF10 1050a $(\mathrm{Co}-10)$, SCARY20830a $(\mathrm{Co}-4)$, SCARAZ20 $_{940 \mathrm{a}}($ Co-6), SCARH13 $490 \mathrm{a}(P h g-1) \mathrm{e}$ OPX11 $550 \mathrm{a}$ (Ur-ON e Co-10) (Alzate-Marin et al., 2005), em que os quatro primeiros são marcadores do tipo SCAR e o último é RAPD. As reações de amplificação foram efetuadas em termociclador Perkin-Elmer, modelo 9600 (Williams et al., 1990). Os produtos de amplificação foram separados em gel de agarose 1,2\%, com $0,2 \mu \mathrm{g} \mathrm{mL}^{-1}$ de brometo de etídeo, imerso em tampão SB (Brody \& Kern, 2004). As bandas de DNA foram visualizadas sob luz ultravioleta e fotografadas com uso do sistema de fotodocumentação Eagle Eye II.

\section{Resultados e Discussão}

A reação dos 31 genótipos e das cultivares testemunhas à inoculação dos patótipos de C. lindemuthianum está apresentada na Tabela 3 . As linhagens UTF-0029, GEN 12, VC 2, GEN 12-2, UTFB-0022, VC 3 e Rudá-R apresentaram reações de 
incompatilibidade a 12 dos 13 patótipos de C. lindemuthianum testados, o que evidencia o fato de esses genótipos serem fontes promissoras de resistência à antracnose. As cultivares $\mathrm{TO}$ e $\mathrm{AB} 136$ foram resistentes a 10 e 12 patótipos de C. lindemuthianum, respectivamente, resultados semelhantes aos encontrados por Ragagnin et al. (2003). No caso da reação da TO ao patótipo 453, os resultados foram contraditórios, pois, segundo esses autores, apresentou resistência e, neste trabalho, suscetibilidade (Tabela 3). A cultivar AB 136 foi suscetível somente ao patótipo 2047. Tais resultados justificam o uso dessas duas cultivares como fontes de genes, em diversos programas de melhoramento que visem resistência a C. lindemuthianum.

A cultivar Ouro Negro apresentou reação incompatível a nove dos 12 patótipos testados, o que indica que é uma boa fonte de resistência à antracnose. Todavia, mostrou-se suscetível ao patótipo 65, conforme já relatado por outros autores (Ragagnin et al., 2003; Faleiro et al., 2004).

As linhagens UTF-0029, GEN 12, VC 2, VC 4, GEN 12-2, VC 5, UTFB-0022, VC 3 e Rudá-R mostraram possuir o mesmo espectro de resistência de TO e AB 136 (Tabela 3), e se destacaram como

Tabela 3. Severidade de antracnose em genótipos de feijão do tipo carioca, com uso de diferentes patótipos de Colletotrichum lindemuthianum.

\begin{tabular}{|c|c|c|c|c|c|c|c|c|c|c|c|c|c|c|}
\hline \multirow{2}{*}{$\overline{\text { Genótipos }}$} & \multirow[t]{2}{*}{$\operatorname{Tipos}^{(1)}$} & \multicolumn{13}{|c|}{ Patótipos de C. lindemuthianum } \\
\hline & & 65 & 67 & 73 & 81 & 83 & 85 & 87 & 89 & 95 & 117 & 453 & 593 & 2047 \\
\hline & & \multicolumn{13}{|c|}{ Severidade $^{(2)}$} \\
\hline Carioca 1070 & $\mathrm{C}$ & 9,0 & 4,2 & 4,0 & 9,0 & 8,0 & 9,0 & 9,0 & 9,0 & 9,0 & 9,0 & 9,0 & 9,0 & 6,0 \\
\hline CNFC 8017 & $\mathrm{~L}$ & 2,3 & 1,0 & 1,0 & 1,6 & 1,0 & 9,0 & 9,0 & 1,0 & 1,7 & 1,0 & 9,0 & 1,2 & 9,0 \\
\hline CNFC 9437 & $\mathrm{~L}$ & 9,0 & 1,0 & 1,0 & 1,0 & 1,0 & 8,0 & 9,0 & 1,0 & 1,0 & 1,0 & 1,0 & 1,0 & 9,0 \\
\hline CNFC 9500 & $\mathrm{~L}$ & 9,0 & 1,0 & 1,2 & 1,0 & 1,0 & 8,0 & 9,0 & 1,0 & 1,0 & 1,0 & 2,6 & 1,0 & 9,0 \\
\hline FT Bonito & $\mathrm{C}$ & 4,0 & 1,0 & 1,0 & 1,0 & 1,0 & 9,0 & 1,9 & 1,0 & 2,0 & 1,0 & 1,0 & 1,0 & 9,0 \\
\hline GEN 12 & $\mathrm{~L}$ & 1,0 & 1,7 & 1,0 & 1,7 & 1,0 & 1,0 & 1,0 & 1,0 & 1,0 & 1,0 & 1,0 & 1,0 & 9,0 \\
\hline GEN 12-2 & $\mathrm{L}$ & 1,0 & 1,0 & 1,5 & 1,0 & 1,0 & 1,0 & 1,0 & 1,0 & 1,0 & 2,2 & 1,0 & 1,0 & 9,0 \\
\hline IAPAR-81 & $\mathrm{C}$ & 4,8 & 4,3 & 2,4 & 5,7 & 2,2 & 9,0 & 5,7 & 5,0 & 4,0 & 9,0 & 8,0 & 7,0 & 7,0 \\
\hline LH-11 & $\mathrm{L}$ & 1,2 & 1,0 & 1,0 & 1,4 & 1,2 & 8,0 & 1,0 & 1,0 & 1,2 & 1,0 & 9,0 & 1,0 & 5,6 \\
\hline LP 98-20 & $\mathrm{L}$ & 9,0 & 9,0 & 7,8 & 8,4 & 7,0 & 9,0 & 9,0 & 7,0 & 8,8 & 8,0 & 9,0 & 9,0 & 9,0 \\
\hline LP 98-76 & $\mathrm{L}$ & 7,8 & 1,7 & 1,0 & 1,0 & 1,0 & 8,4 & 5,5 & 1,2 & 2,6 & 1,0 & 1,0 & 1,0 & 8,8 \\
\hline LP-98-31 & $\mathrm{L}$ & 9,0 & 1,0 & 2,3 & 1,3 & 1,5 & 8,0 & 9,0 & 1,0 & 1,7 & 1,7 & 1,0 & 2,4 & 9,0 \\
\hline OPS-82 & $\mathrm{L}$ & 9,0 & 1,0 & 1,0 & 1,7 & 1,0 & 8,0 & 7,0 & 1,0 & 1,6 & 1,0 & 1,0 & 1,0 & 9,0 \\
\hline Pérola & $\mathrm{C}$ & 9,0 & 7,7 & 4,0 & 9,0 & 7,0 & 9,0 & 9,0 & 9,0 & 9,0 & 9,0 & 9,0 & 9,0 & 9,0 \\
\hline Talismã & $\mathrm{C}$ & 2,0 & 1,0 & 1,0 & 1,0 & 2,0 & 9,0 & 4,0 & 1,0 & 1,0 & 1,0 & 9,0 & 1,0 & 9,0 \\
\hline UTF-0013 & $\mathrm{L}$ & 9,0 & 4,0 & 4,5 & 1,5 & 3,1 & 9,0 & 7,4 & 2,4 & 1,8 & 2,6 & 9,0 & 1,0 & 9,0 \\
\hline UTF-0019 & $\mathrm{L}$ & 6,5 & 8,2 & 6,7 & 6,1 & 7,2 & 9,0 & 9,0 & 7,4 & 2,4 & 7,2 & 9,0 & 9,0 & 9,0 \\
\hline UTF-0029 & $\mathrm{L}$ & 2,4 & 2,3 & 2,0 & 1,3 & 1,0 & 1,0 & 2,2 & 1,6 & 1,7 & 2,3 & 1,0 & 1,0 & 9,0 \\
\hline UTF-0030 & $\mathrm{L}$ & 4,5 & 3,0 & 2,0 & 2,2 & 2,2 & 6,1 & 2,3 & 3,0 & 5,0 & 1,7 & 3,0 & 1,0 & 8,8 \\
\hline UTF-0031 & $\mathrm{L}$ & 1,5 & 1,0 & 1,7 & 1,0 & 1,7 & 6,3 & 5,0 & 1,0 & 1,0 & 1,0 & 5,0 & 5,1 & 9,0 \\
\hline UTF-0037 & $\mathrm{L}$ & 3,0 & 4,0 & 4,0 & 1,6 & 1,0 & 1,0 & 1,0 & 1,0 & 1,0 & 1,6 & 1,7 & 3,2 & 9,0 \\
\hline UTFB-0018 & $\mathrm{L}$ & 2,2 & 1,0 & 1,0 & 1,5 & 1,0 & 9,0 & 4,2 & 1,0 & 1,0 & 1,0 & 2,7 & 1,0 & 9,0 \\
\hline UTFB-0022 & $\mathrm{L}$ & 1,6 & 1,0 & 1,0 & 1,0 & 1,8 & 1,6 & 1,9 & 1,0 & 1,0 & 1,7 & 1,0 & 1,0 & 9,0 \\
\hline VC 2 & $\mathrm{~L}$ & 1,0 & 1,0 & 1,0 & 1,0 & 1,0 & 1,0 & 1,0 & 2,3 & 1,0 & 1,6 & 1,0 & 1,0 & 9,0 \\
\hline VC 3 & $\mathrm{~L}$ & 1,0 & 1,0 & 1,0 & 1,0 & 1,0 & 1,0 & 2,1 & 1,7 & 1,0 & 1,0 & 1,0 & 1,0 & 9,0 \\
\hline VC 4 & $\mathrm{~L}$ & 1,7 & 1,8 & 1,8 & 1,0 & 2,2 & 1,0 & 8,0 & 1,5 & 1,7 & 2,8 & 2,8 & 1,0 & 9,0 \\
\hline VC 5 & $\mathrm{~L}$ & 1,0 & 1,0 & 1,0 & 1,0 & 1,0 & 1,0 & 6,0 & 1,0 & 1,0 & 1,0 & 1,0 & 1,0 & 9,0 \\
\hline Vi 0699 & $\mathrm{~L}$ & 8,3 & 1,0 & 1,4 & 1,0 & 1,0 & 8,6 & 8,0 & 1,0 & 1,0 & 1,5 & 1,0 & 1,0 & 9,0 \\
\hline Vi-4599 & $\mathrm{L}$ & 9,0 & 5,0 & 6,6 & 4,6 & 4,1 & 9,0 & 9,0 & 2,8 & 3,6 & 6,4 & 4,3 & 1,0 & 8,0 \\
\hline Vi-4899 & $\mathrm{L}$ & 9,0 & 1,7 & 1,9 & 1,0 & 2,2 & 9,0 & 9,0 & 1,0 & 1,0 & 1,0 & 9,0 & 1,0 & 9,0 \\
\hline Rudá-R & $\mathrm{L}$ & 1,0 & 1,0 & 1,0 & 1,0 & 1,0 & 1,0 & 1,0 & 1,0 & 1,0 & 1,0 & 1,0 & 1,0 & 8,8 \\
\hline $\mathrm{TO}^{(3)}$ & $\mathrm{C}$ & 1,0 & 1,0 & 1,0 & 1,0 & 1,0 & 1,0 & 1,0 & 1,0 & 1,0 & 1,0 & 9,0 & 5,0 & 8,0 \\
\hline AB $136^{(3)}$ & $\mathrm{C}$ & 1,0 & 1,0 & 1,0 & 1,0 & 1,0 & 1,0 & 1,0 & 1,0 & 1,0 & 1,0 & 1,0 & 1,0 & 9,0 \\
\hline Ouro Negro $^{(3)}$ & $\mathrm{C}$ & 9,0 & 2,3 & 1,0 & 1,0 & 1,0 & 8,0 & 9,0 & 1,0 & 1,0 & 1,0 & 1,0 & 1,0 & $-(5)$ \\
\hline Rudá $^{(4)}$ & $\mathrm{C}$ & 9,0 & 9,0 & 9,0 & 9,0 & 9,0 & 9,0 & 9,0 & 9,0 & 8,8 & 9,0 & 9,0 & 9,0 & 9,0 \\
\hline
\end{tabular}

${ }^{(1)} \mathrm{L}$, linhagem; C, cultivar. ${ }^{(2)}$ Severidade média de antracnose, com uso de escala de 1 a 9; notas iguais ou superiores a 3,1 caracterizam suscetibilidade.

${ }^{(3)}$ Fontes de genes de resistência à antracnose. ${ }^{(4)}$ Testemunha suscetível ${ }^{(5)}$ Não avaliado. 
novas opções de fonte de resistência à antracnose. Os genótipos Vi-4599, Pérola, LP 98-20, Carioca 1070, IAPAR-81 e UTF-0019 foram suscetíveis a pelo menos 11 dos 13 patótipos de C. lindemuthianum testados. Todas as linhagens avaliadas foram suscetíveis ao patótipo 2047, ainda não identificado no Brasil.

Assim, os programas de melhoramento do Brasil precisam prospectar novas fontes de genes de resistência a esse patótipo, como estratégia para se antecipar a futuros problemas, para reduzir a vulnerabilidade genética do hospedeiro e, conseqüentemente, permitir o cruzamento com genótipos mais adaptados e seleção de novas linhagens promissoras, com grãos do tipo carioca, resistentes ao patótipo 2047.

A cultivar Talismã foi resistente aos patótipos 65, 67, $73,81,83,89,95$ e 117, tendo-se destacado em relação à Pérola, que foi suscetível a todos os patótipos testados. Apesar de sua suscetibilidade à antracnose, a cultivar Pérola ainda é uma das mais cultivadas no Brasil, em razão do bom potencial de rendimento e excelente qualidade dos grãos (Embrapa, 2007).

$\mathrm{Na}$ avaliação das linhagens quanto à reação aos patótipos de P. griseola (Tabela 4), AND 277 comportou-se como resistente a seis dos sete patótipos

Tabela 4. Severidade de ferrugem e mancha-angular, em genótipos de feijão do tipo carioca, com uso de diferentes patótipos de Uromyces appendiculatus e Pseudocercospora griseola.

\begin{tabular}{|c|c|c|c|c|c|c|c|c|c|c|}
\hline \multirow[t]{2}{*}{ Genótipos } & \multirow[t]{2}{*}{$\operatorname{Tipos}^{(1)}$} & \multicolumn{2}{|c|}{$\begin{array}{c}\text { Patótipos de } \\
\text { U. appendiculatus }\end{array}$} & \multicolumn{7}{|c|}{ Patótipos de $P$. griseola } \\
\hline & & $29-3$ & $63-3$ & 31.15 & 31.23 & 31.39 & 63.19 & 63.23 & 63.31 & 63.55 \\
\hline & & \multicolumn{9}{|c|}{ Severidade $^{(2)}$} \\
\hline Carioca 1070 & $\mathrm{C}$ & 6,0 & 6,0 & $7,9^{(2)}$ & 6,7 & 7,3 & 6,8 & 7,7 & 8,2 & 8,6 \\
\hline CNFC 8017 & $\mathrm{~L}$ & 1,0 & 1,0 & 7,3 & 8,4 & 8,0 & 6,7 & 5,8 & 7,9 & 8,9 \\
\hline CNFC 9437 & $\mathrm{~L}$ & 3,2 & 5,0 & 7,4 & 8,3 & 1,1 & 8,1 & 4,9 & 7,7 & 1,9 \\
\hline CNFC 9500 & $\mathrm{~L}$ & 4,6 & 6,0 & 8,5 & 9,0 & 3,1 & 7,5 & 5,5 & 8,1 & 7,5 \\
\hline GEN 12 & $\mathrm{~L}$ & 6,0 & 6,0 & 1,9 & 3,2 & 1,2 & 1,6 & 1,0 & 6,6 & 4,3 \\
\hline GEN 12-2 & $\mathrm{L}$ & 6,0 & 6,0 & 4,2 & 3,1 & 2,8 & 2,3 & 2,5 & 5,8 & 8,5 \\
\hline IAPAR-81 & $\mathrm{C}$ & 6,0 & 6,0 & 3,9 & 6,8 & 1,2 & 5,4 & 7,8 & 7,5 & 7,8 \\
\hline LH-11 & $\mathrm{L}$ & 6,0 & 6,0 & 7,9 & 8,2 & 8,9 & 4,9 & 3,6 & 7,9 & 9,0 \\
\hline LP 98-20 & $\mathrm{L}$ & 3,0 & 5,0 & 1,0 & 1,0 & 4,7 & 1,0 & 1,0 & 1,0 & 9,0 \\
\hline LP 98-76 & $\mathrm{L}$ & 3,2 & 5,0 & 8,0 & 8,8 & 4,7 & 8,5 & 5,6 & 8,0 & 6,3 \\
\hline LP-98-31 & $\mathrm{L}$ & 4,0 & 6,0 & 8,5 & 8,4 & 1,0 & 6,1 & 6,0 & 7,8 & 1,3 \\
\hline Pérola & $\mathrm{C}$ & 1,0 & 3,0 & 5,5 & 7,8 & 6,8 & 4,1 & 8,9 & 7,0 & 8,9 \\
\hline Talismã & $\mathrm{C}$ & 1,0 & 4,0 & 1,5 & 2,3 & 1,3 & 5,1 & 1,7 & 5,7 & 8,4 \\
\hline UTF-0013 & $\mathrm{L}$ & 6,0 & 6,0 & 1,2 & 1,4 & 1,4 & 1,0 & 1,1 & 5,7 & 6,9 \\
\hline UTF-0019 & $\mathrm{L}$ & 6,0 & 6,0 & 1,2 & 4,2 & 2,1 & 4,6 & 7,3 & 7,8 & 1,3 \\
\hline UTF-0029 & $\mathrm{L}$ & 6,0 & 6,0 & 2,6 & 3,0 & 1,0 & 1,6 & 1,0 & 5,6 & 8,7 \\
\hline UTF-0030 & $\mathrm{L}$ & 6,0 & 6,0 & 1,6 & 8,7 & 1,6 & 4,4 & 4,5 & 7,3 & 8,6 \\
\hline UTF-0031 & $\mathrm{L}$ & 6,0 & 6,0 & 1,0 & 4,2 & 1,1 & 3,9 & 5,9 & 5,7 & 2,6 \\
\hline UTF-0037 & $\mathrm{L}$ & 6,0 & 6,0 & 2,7 & 2,1 & 1,0 & 1,0 & 2,6 & 5,9 & 6,5 \\
\hline UTFB-0018 & $\mathrm{L}$ & 1,0 & 1,0 & 4,5 & 2,7 & 1,0 & 1,0 & 1,0 & 5,3 & 8,3 \\
\hline UTFB-0022 & $\mathrm{L}$ & 6,0 & 6,0 & 2,1 & 2,0 & 1,4 & 1,5 & 1,9 & 4,9 & 7,3 \\
\hline VC 2 & $\mathrm{~L}$ & 1,0 & 1,3 & 1,0 & 1,7 & 5,4 & 2,4 & 1,0 & 1,1 & 8,9 \\
\hline VC 3 & $\mathrm{~L}$ & 1,0 & 4,0 & 1,0 & 1,0 & 7,1 & 1,0 & 1,2 & 1,0 & 8,8 \\
\hline VC 4 & $\mathrm{~L}$ & 1,0 & 1,0 & 7,3 & 8,6 & 6,1 & 6,9 & 7,7 & 7,9 & 9,0 \\
\hline VC 5 & $\mathrm{~L}$ & 1,0 & 1,0 & 1,4 & 1,0 & 4,1 & 1,0 & 1,0 & 1,7 & 9,0 \\
\hline Vi-0699 & $\mathrm{L}$ & 1,3 & 1,0 & 6,8 & 9,0 & 7,0 & 5,8 & 6,7 & 8,2 & 8,9 \\
\hline Rudá-R & $\mathrm{L}$ & 1,0 & 1,0 & 1,2 & 1,0 & 8,0 & 1,0 & 1,0 & 2,2 & 9,0 \\
\hline Ouro Negro ${ }^{(3)}$ & $\mathrm{C}$ & 1,2 & 2,0 & 6,4 & 7,5 & 1,2 & 8,7 & 2,0 & 7,6 & 2,0 \\
\hline Rudá(4) & $\mathrm{C}$ & 5,6 & 6,0 & 9,0 & 8,8 & 8,5 & 9,0 & 9,0 & 9,0 & 9,0 \\
\hline AND $277^{(5)}$ & $\mathrm{C}$ & 6,0 & 6,0 & 1,6 & 1,2 & 1,0 & 3,2 & 1,0 & 2,5 & 9,0 \\
\hline
\end{tabular}

${ }^{(1)}$ L, linhagem; C, cultivar. ${ }^{(2)}$ Graus de severidade iguais ou superiores a 3,1 caracterizam suscetibilidade. ${ }^{(3)}$ Testemunha resistente à ferrugem. ${ }^{(4)}$ Testemunha suscetível à ferrugem e à mancha-angular. ${ }^{(5)}$ Testemunha resistente à mancha-angular. 
de $P$. griseola testados, resultados semelhantes aos obtidos por Ragagnin et al. (2003). Além da AND 277, os genótipos UTFB-0018, UTF-0029, GEN 12, UTF-0013, LP 98-20, VC 2, UTF-0037, VC 5, OPS-82, UTFB-0022, Talismã, VC 3 e Rudá-R apresentaram bons níveis de resistência à $P$. griseola, com destaque para a linhagem LP 98-20. Por sua vez, os genótipos Pérola, Carioca 1070, CNFC 9500, CNFC 8017, VC 4, Vi-0669, Vi-4899, LH-11, LP 98-76 e Rudá foram suscetíveis a todos os patótipos testados. A suscetibilidade da cultivar Pérola a vários patótipos de $P$. griseola já foi relatada por Faleiro et al. (2001).

Todos os genótipos avaliados foram suscetíveis a pelo menos um dos sete patótipos de P. griseola testados. O patótipo 63.55 foi o mais virulento entre os de $P$. griseola testados, tendo causado reação de compatibilidade em 27 dos 31 genótipos avaliados, além das cultivares Rudá e AND 277. Esse resultado está de acordo com os encontrados por Nietsche et al. (2001) e Sartorato \& Alzate-Marin (2004), que verificaram que o referido patótipo causou doença em pelo menos dez das 12 cultivares diferenciadoras. Isso demonstra que o patótipo possui alta virulência para infectar diferentes genótipos do feijoeiro. Todavia, as linhagens LP-98-31, UTF-0031, UTF-0019 e CNFC 9437 e a cultivar Ouro Negro foram as únicas resistentes ao patótipo 63.55. Assim, são importantes fontes de genes de resistência a serem utilizadas em intercruzamentos, principalmente em programas de melhoramento que desenvolvem cultivares para os Estados de Goiás e Minas Gerais, locais de maior ocorrência do patótipo 63.55 (Sartorato \& Alzate-Marin, 2004).

Vinte e quatro linhagens de feijão foram suscetíveis a pelo menos um dos dois patótipos de $U$. appendiculatus testados. A linhagem Rudá-R e as linhagens UTFB-0018, CNFC 8017, VC 4 e VC 5 apresentaram nota 1 aos dois patótipos (Tabela 4). Os genótipos Vi-4599, Pérola, VC 2, Vi-0699 e Vi-4899 apresentaram bons níveis de resistência.

A cultivar Ouro Negro foi resistente aos dois patótipos de U. appendiculatus testados (Tabela 4). Ragagnin et al. (2003) avaliaram a reação da cultivar Ouro Negro a dez patótipos de $U$. appendiculatus e detectaram resistência da cultivar a todos os patótipos. Por isso, essa cultivar vem sendo empregada como doadora de genes de resistência a patótipos de $U$. appendiculatus, caracterizados no Brasil em programas de melhoramento de feijão que utilizam hibridação (Faleiro et al., 2004).
As linhagens Vi-0699, Vi-4599 e Vi-4899 apresentaram espectro de resistência à ferrugem bastante semelhante a cultivar Ouro Negro, especialmente a Vi-0699 (Tabela 4). Esse resultado era esperado, pelo fato de tais linhagens serem provenientes de retrocruzamentos assistidos por marcadores moleculares, nos quais as cultivares Rudá e Ouro Negro foram usadas como parentais (Faleiro et al., 2004).

As linhagens VC 2, VC 5, VC 3 e Rudá-R foram as que apresentaram maior espectro de resistência aos três patógenos, de acordo com a caracterização fenotípica realizada no presente trabalho. Esses genótipos são importantes fontes de resistência, que podem ser utilizados em programas de melhoramento do feijoeiro com diferentes esquemas de intercruzamentos e seleções, para a obtenção de novas cultivares com resistência múltipla a C. lindemuthianum, U. appendiculatus e P. griseola.

A caracterização molecular foi realizada com o intuito de verificar o polimorfismo entre os 30 possíveis genitores com a Rudá-R, com a possibilidade de se usar algum desses marcadores, previamente identificados, para a seleção indireta em populações segregantes que envolvam algum desses genitores e a Rudá-R (Tabela 5). Por exemplo, os genótipos GEN 12-2, UTF-0037, FT Bonito, UTF-0031, IAPAR-81, entre outros, apresentaram suscetibilidade aos dois patótipos de $U$.appendiculatus e não possuem a marca OPX11 (Ur-ON). Outros casos são os das linhagens UTF-0013, LP 98-20, Vi-0699, OPS 82, entre outros, que foram suscetíveis ao patótipo 65 de $C$. lindemuthianum e não possuem a banda do marcador SCARY20 (Co-4). Podem-se citar também os casos dos genótipos Carioca 1070, CNFC 8017, VC 4, Vi-0699, entre outros, os quais foram suscetíveis a todos os patótipos de P. griseola e não apresentaram o marcador SCARH13 (Phg-1) (Tabela 5). Esses genitores, quando intercruzados com a Rudá-R, podem gerar linhagens resistentes aos patógenos avaliados com a presença dos marcadores específicos, os quais podem ser detectados por meio da seleção assistida das populações segregantes.

Alguns genótipos expressaram a resistência à maioria dos patótipos de $C$. lindemuthianum, $U$. appendiculatus e P. griseola, fenotipicamente, como é o caso das linhagens $\mathrm{VC} 2, \mathrm{VC} 3$, mas não possuem a banda dos marcadores específicos. Esses resultados são explicados pelo fato de a literatura demonstrar que os genes $\mathrm{Co}, \mathrm{Ur}$ e Phg, bem como os genes $\mathrm{R}$ em geral, estão em uma série multialélica ou em agrupamentos gênicos no nível molecular, apesar de se comportarem como genes de 
efeito principal (Ferrier-Cana et al., 2003; Miklas et al., 2006). Portanto, apesar de a caracterização fenotípica detectar resistência nas linhagens VC 2 e VC 3, no nível molecular os marcadores não foram capazes de detectar as regiões do genoma circunvizinhas aos alelos específicos, as quais podem conferir a resistência na ausência desses alelos específicos. Esse fato pode também ser explicado pelo possível erro do marcador. Quanto mais distante o marcador estiver do alelo específico, maior será a chance de ocorrer uma recombinação e ser perdida a ligação do marcador com o alelo específico.

Dez linhagens apresentaram o produto de amplificação do marcador SCARAZ20 ${ }_{845 a}$, ligado ao alelo Co-6 de resistência à antracnose. Oito linhagens apresentaram os marcadores SCARF10 1050a $\mathrm{e}$ OPX11 ${ }_{550 \mathrm{a}}$, ligados aos alelos de resistência à ferrugem e à antracnose $(U r-O N$ e $C o-10)$, e ao alelo de resistência à ferrugem $(U r-O N)$, respectivamente. O marcador SCARH13 $520 \mathrm{a}$ foi detectado em seis linhagens. O marcador SCARY20 830 a, ligado ao alelo $\mathrm{Co}-4$, foi detectado somente na Rudá-R. As linhagens LP-98-31, UTF-0029, Vi-4599C, GEN 12, CNFC 9500 e Vi-4899C apresentaram pelo menos dois dos cinco marcadores utilizados no presente trabalho (Tabela 5). A Rudá-R foi a única linhagem em que foram detectadas todas as bandas dos marcadores moleculares utilizados no presente trabalho, o que confirma os resultados obtidos por Ragagnin (2004).

Tabela 5. Caracterização molecular de genótipos de feijão do tipo carioca, com uso de marcadores moleculares ligados a genes de resistência à antracnose, ferrugem e mancha-angular.

\begin{tabular}{|c|c|c|c|c|c|c|}
\hline \multirow[t]{2}{*}{ Genótipos } & \multirow[t]{2}{*}{$\operatorname{Tipos}^{(1)}$} & \multicolumn{5}{|c|}{ Marcadores moleculares } \\
\hline & & $\begin{array}{l}\text { SCARAZ20 } \\
(\mathrm{Co}-6)^{(2)}\end{array}$ & $\begin{array}{l}\text { SCARF10 } \\
(\mathrm{Co}-10)^{(2)}\end{array}$ & $\begin{array}{l}\text { SCARH13 } \\
(P h g-1)^{(2)}\end{array}$ & $\begin{array}{l}\text { SCARY20 } \\
(\mathrm{Co}-4)^{(2)}\end{array}$ & $\begin{array}{c}\text { OPX11 } \\
(U r-O N)^{(2)}\end{array}$ \\
\hline & & & & Caracterização & & \\
\hline Carioca 1070 & $\mathrm{C}$ & 0 & 0 & 0 & 0 & 0 \\
\hline CNFC 8017 & $\mathrm{~L}$ & 0 & 0 & 0 & 0 & 0 \\
\hline CNFC 9437 & $\mathrm{~L}$ & 0 & 1 & 0 & 0 & 0 \\
\hline CNFC 9500 & $\mathrm{~L}$ & 1 & 0 & 0 & 0 & 1 \\
\hline FT Bonito & $\mathrm{C}$ & 1 & 0 & 0 & 0 & 0 \\
\hline GEN 12 & $\mathrm{~L}$ & 1 & 0 & 1 & 0 & 0 \\
\hline GEN 12-2 & $\mathrm{L}$ & 0 & 0 & 0 & 0 & 0 \\
\hline IAPAR-81 & $\mathrm{C}$ & 0 & 0 & 0 & 0 & 0 \\
\hline LH-11 & $\mathrm{L}$ & 0 & 0 & 0 & 0 & 0 \\
\hline LP 98-20 & $\mathrm{L}$ & 0 & 1 & 0 & 0 & 0 \\
\hline LP 98-76 & $\mathrm{L}$ & 0 & 1 & 0 & 0 & 0 \\
\hline LP 98-31 & $\mathrm{L}$ & 1 & 1 & 0 & 0 & 1 \\
\hline OPS-82 & $\mathrm{L}$ & 0 & 0 & 0 & 0 & 1 \\
\hline Pérola & $\mathrm{C}$ & 0 & 0 & 0 & 0 & 0 \\
\hline Talismã & $\mathrm{C}$ & 0 & 0 & 0 & 0 & 0 \\
\hline UTF-0013 & $\mathrm{L}$ & 0 & 0 & 1 & 0 & 0 \\
\hline UTF-0019 & $\mathrm{L}$ & 0 & 0 & 0 & 0 & 1 \\
\hline UTF-0029 & $\mathrm{L}$ & 1 & 0 & 1 & 0 & 0 \\
\hline UTF-0030 & $\mathrm{L}$ & 0 & 1 & 0 & 0 & 0 \\
\hline UTF-0031 & $\mathrm{L}$ & 0 & 0 & 0 & 0 & 0 \\
\hline UTF-0037 & $\mathrm{L}$ & 0 & 0 & 0 & 0 & 0 \\
\hline UTFB-0018 & $\mathrm{L}$ & 1 & 0 & 0 & 0 & 0 \\
\hline UTFB-0022 & $\mathrm{L}$ & 0 & 1 & 0 & 0 & 0 \\
\hline VC 2 & $\mathrm{~L}$ & 0 & 0 & 1 & 0 & 0 \\
\hline VC 3 & $\mathrm{~L}$ & 0 & 0 & 0 & 0 & 0 \\
\hline VC 4 & $\mathrm{~L}$ & 0 & 0 & 0 & 0 & 0 \\
\hline VC 5 & $\mathrm{~L}$ & 1 & 0 & 0 & 0 & 0 \\
\hline Vi 0699 & $\mathrm{~L}$ & 0 & 0 & 0 & 0 & 1 \\
\hline Vi-4599 & $\mathrm{L}$ & 1 & 0 & 1 & 0 & 1 \\
\hline Vi-4899 & $\mathrm{L}$ & 1 & 1 & 0 & 0 & 1 \\
\hline Rudá-R & $\mathrm{L}$ & 1 & 1 & 1 & 1 & 1 \\
\hline
\end{tabular}

${ }^{(1)} \mathrm{L}$, linhagem; C, cultivar. ${ }^{(2)}$ Alelos de resistência ligados aos respectivos marcadores. ${ }^{(3)}$ Valor 1 para plantas com presença da marca e valor 0 para plantas com ausência da marca. 
Observa-se, então, que a maioria dos genótipos de feijão de grãos tipo carioca avaliados não possui espectros satisfatórios de resistência múltipla à antracnose, ferrugem e mancha-angular, o que evidencia a necessidade de maior empenho dos programas de melhoramento do feijoeiro nesse sentido. Algumas linhagens, porém, se mostraram resistentes aos patótipos testados e se constituem em boa opção para serem utilizadas como fontes de genes mais adaptados, na tentativa de se desenvolverem cultivares com resistência múltipla a essas doenças em menor período, em comparação ao uso de fontes de resistência exóticas. Aliada a isso, a caracterização molecular demonstrou a possibilidade de uso de marcadores moleculares, por meio da seleção assistida, nas etapas iniciais de um programa de melhoramento, em linhagens decorrentes do intercruzamento entre as linhagens elites e as cultivares testadas neste trabalho, suscetíveis fenotipicamente, e com ausência dos marcadores moleculares testados neste trabalho, com a Rudá-R.

\section{Conclusões}

1. Os genótipos Rudá-R, VC 2, VC 3 e VC 5 são excelentes fontes de genes de resistência à antracnose, ferrugem e mancha-angular, para serem prontamente utilizadas em programas de melhoramento do feijoeiro.

2. Os genótipos Carioca 1070, IAPAR-81, Pérola, UTF-0019, além da Rudá, apresentam alto nível de suscetibilidade aos patógenos da antracnose, ferrugem e mancha-angular, de acordo com a caracterização fenotípica e ausência dos marcadores moleculares.

3. Cruzamentos de Rudá-R com genótipos suscetíveis, tanto fenotípica quanto molecularmente, possibilitam o uso dos cinco marcadores moleculares, para seleção assistida de linhagens resistentes aos patógenos avaliados.

\section{Referências}

ALZATE-MARIN, A.L.; CERVIGNI, G.D.L.; MOREIRA, M.A.; BARROS, E.G. Seleção assistida por marcadores moleculares visando ao desenvolvimento de plantas resistentes a doenças, com ênfase em feijoeiro e soja. Fitopatologia Brasileira, v.30, p.333-342, 2005.

ALZATE-MARIN, A.L.; SARTORATO, A. Analysis of the pathogenic variability of Colletotrichum lindemuthianum in Brazil. Annual Report of Bean Improvement Cooperative, v.47, p.241-242, 2004.

BALARDIN, R.S.; JAROSZ, A.; KELLY, J.D. Virulence and molecular diversity in Colletotrichum lindemuthianum from South,
Central and North America. Phytopathology, v.87, p.1184-1191, 1997.

BRODY, J.R.; KERN, S.E. Sodium boric acid: a Tris-free, cooler conductive medium for DNA electrophoresis. BioTechniques, v.36, p.214-216, 2004.

DEL PELOSO, M.J.; MELO, L.C.; FARIA, L.C.; COSTA, J.G.C.; RAVA, C.A.; CARNEIRO, G.E.S.; SOARES, D.M.; DÍAZ, J.L.C.; ABREU, A. de F.B.; FARIA, J.C.; SARTORATO, A.; SILVA, H.T.; BASSINELLO, P.Z.; ZIMMERMANN, F.J.P. BRS PONTAL: new common bean cultivar with carioca grain type. Annual Report of Bean Improvement Cooperative, v.47, p.323-324, 2004.

EMBRAPA. Cultivar Pérola. Disponível em: http:// www.cnpaf.embrapa.br/feijao/perola.htm. Acesso em: 15 jun. 2007.

EMBRAPA. Cultivar Rudá. Disponível em: http:// www.cnpaf.embrapa.br/feijao/ruda.htm. Acesso em: 22 fev. 2008.

FALEIRO, F.G.; NIETSCHE, S.; RAGAGNIN, V.A.; BORÉM, A.; MOREIRA, M.A.; BARROS, E.G. Resistência de cultivares de feijoeiro-comum à ferrugem e à mancha-angular em condições de casa de vegetação. Fitopatologia Brasileira, v.26, p.86-89, 2001.

FALEIRO, F.G.; RAGAGNIN, V.A.; MOREIRA, M.A.; BARROS, E.G. Use of molecular markers to accelerate the breeding of common bean lines resistant to rust and anthracnose. Euphytica, v.138, p.213-218, 2004.

FALEIRO, F.G.; VINHADELLI, W.S.; RAGAGNIN, V.A.; ZAMBOLIM, L.; PAULA JÚNIOR, T.J.; MOREIRA, M.A.; BARROS, E.G. Identificação de raças fisiológicas de Uromyces appendiculatus no Estado de Minas Gerais, Brasil. Fitopatologia Brasileira, v.24, p.166-169, 1999.

FARIA, L.C.; COSTA, J.G.C.; RAVA, C.A.; DEL PELOSO, M.J.; MELO, L.C.; CARNEIRO, G.E.S.; SOARES, D.M.; DÍAZ, J.L.C.; ABREU, A. de F.B.; FARIA, J.C.; SARTORATO, A.; SILVA, H.T.; BASSINELLO, P.Z.; ZIMMERMANN, F.J.P. BRS REQUINTE: new common bean carioca cultivar with delayed grain darkness. Annual Report of Bean Improvement Cooperative, v.47, p.315-316, 2004.

FERRIER-CANA, E.; GEFFROY, V.; MACADRÉ, C.; CREUSOT, F.; IMBERT-BOLLORÉ, P.; SEVIGNAC, M.; LANGIN, T. Characterization of expressed NBS-LRR resistance gene candidates from common bean. Theoretical and Applied Genetics, v.106, p.251-261, 2003.

MIKLAS, P.N.; KELLY, J.D.; BEEBE, S.E.; BLAIR, M.W. Common bean breeding for resistance against biotic and abiotic stresses: from classical to MAS breeding. Euphytica, v.147, p.105-131, 2006.

NIETSCHE, S.; BORÉM, A.; CARVALHO, G.A.; PAULAJÚNIOR, T.J.; FONTES-FERREIRA, C.F.; BARROS, E.G.; MOREIRA, M.A. Genetic diversity of Phaeoisariopsis griseola in the State of Minas Gerais, Brazil. Euphytica, v.117, p.77-84, 2001.

PAULA JÚNIOR, T.J.; ZAMBOLIM, L. Doenças. In: VIEIRA, C.; PAULA JÚNIOR, T.J.; BORÉM, A. (Ed.). Feijão. Viçosa: UFV, 2006. p.359-414.

PIO-RIBEIRO, G.; CHAVES, G.M. Raças fisiológicas de Colletotrichum lindemuthianum (Sacc. et Magn.) Scrib. que ocorrem em alguns municípios de Minas Gerais, Espírito Santo e Rio de Janeiro. Experientiae, v.19, p.95-118, 1975. 
RAGAGNIN, V.A. Piramidação de genes de resistência à ferrugem, antracnose e mancha-angular em feijão do tipo carioca. 2004. 79p. Tese (Doutorado) - Universidade Federal de Viçosa, Viçosa.

RAGAGNIN, V.A.; ALZATE-MARIN, A.L.; SOUZA, T.L.P.O.; ARRUDA, K.M.A.; MOREIRA, M.A.; BARROS, E.G. Avaliação da resistência de isolinhas de feijoeiro a diferentes patótipos de Colletotrichum lindemuthianum, Uromyces appendiculatus e Phaeoisariopsis griseola. Fitopatologia Brasileira, v.28, p.591-596, 2003.

SARTORATO, A.; ALZATE-MARIN, A.L. Analysis of the pathogenic variability of Phaeoisariopsis griseola in Brazil. Annual Report of Bean Improvement Cooperative, v.47, p.235-236, 2004.

SARTORATO, A.; DEL PELOSO, M.J.; RAVA, C.A.; COSTA, J.G.C.; FARIA, L.C.; MELO, L.C. Bean reactions to 24 pathotypes of Colletotrichum lindemuthianum. Annual Report of Bean Improvement Cooperative, v.47, p.247-248, 2004.
SILVA, K.J.D. Distribuição e caracterização de isolados de Colletotrichum lindemuthianum no Brasil. 2004. 88p. Tese (Mestrado) - Universidade Federal de Lavras, Lavras.

SOUZA, T.L.P.O. Classificação de raças fisiológicas de Uromyces appendiculatus e piramidação de genes de resistência ao patógeno em feijão do tipo carioca. 2005. 98p. Tese (Mestrado) Universidade Federal de Viçosa, Viçosa.

STAVELY, J.R.; FREYTAG, G.F.; STEADMAN, J.R.; SCHWARTZ, H.F. The bean rust workshop. Annual Report of Bean Improvement Cooperative, v.26, p.4-6, 1983.

VAN SCHOONHOVEN, A.; PASTOR-CORRALES, M.A. Standard system for evaluation of bean germplasm. Cali: CIAT, 1987. 53p.

WILLIAMS, J.G.; KUBELIK, A.R.; LIVAK, K.J.; RAFALSKI, L.A.; TINGEY, S.V. DNA polymorphisms amplified by arbitrary primers are useful as genetic markers. Nucleic Acids Research, v.18, p.6531-6535, 1990.

Recebido em 9 de novembro de 2007 e aprovado em 9 de abril de 2008 